\title{
Environmental Risks in Open Pit Mines: Representation of a Temporal Evolution Related to Water Factor
}

\author{
S. B. Mondoukpè Lagnika \\ École de technologie supérieure, Canada
}

Robert Hausler

Department of construction engineering, École de technologie supérieure, Canada

Received: August 22, 2018 Accepted: September 13, 2018 Published: September 18, 2018

doi:10.5296/emsd.v7i4.13534 URL: https://doi.org/10.5296/emsd.v7i4.13534

\begin{abstract}
Natural resources are sources of much ecological instability. They are subjects of many types of research and led to the strengthening of measures. However, the exposure to hazards (water-air-soil pollution, radiation, degradation, etc.) due to such industries as mining continuous. This paper intends to show the dynamic relationships between production and time as part of the synergy of the whole extraction system over time. Given to sensitives issues known in the heart of mining operations, water is, therefore, the only environmental factor considered to lighten the research methodology. So, after the hypothesis, a temporal graphic with time and mining production level as explanatory and dependent variables is developed. Then, attention is given to the hypothesis validation used to highlight the joint result of the two variables. This is done by a literature review on environmental management risks tools existing, in-depth on the open pit mines with the simple linear regression analysis. The paired T-test Student result will help to clarify the potential of this statistical approach.
\end{abstract}

Keywords: Environment, Mines, Risks, Temporal, Dynamic, System, Over time

\section{Introduction and Scope of Study}

The increase of industrial activity in recent decades has revolutionized many lifestyles since the industrial revolution. The various ores processing levels into products of public or individual utility are known to be a source of a whole range of risks most of whom start at every step of ore extraction from its natural environment (Kř́ibeka, De Vivob, \& Davies, 2014; Peck \& Sinding, 2003; Singh, Ihlenfeld, Oates, Plant, \& Voulvoulis, 2011). Accordingly, several environmental factors (EFs) are affected despite the diversity of environmental management tools available. But, among these EFs, water, although tied up to basic needs of 
all life on earth, is also intrinsically linked to mining operations and essential to industrial activities. Indeed, in mining, there were millions of cubic meters are used, and millions of cubic meters of waste water are produced (Statcan, 2012). This because of, its use in the extraction process (drilling), production (crushing) and, in processing of minerals (enrichment). These lead to an ecological instability highlighted since the Rio conference (1992) and subject to in-depth discussions of many authors like Kalabin (2012), Pokhrel and Dubey (2013) but, also lead to dynamic impacts.

Any system evolves. It is so for the ecosystem components as well as for phenomena such as risks, and especially here by those related to the environment. In open pit (OP) mines case, risks evolve and have different consequences on the living environment. Many studies expose the mining ecological challenges despite the solutions developed (Lintukangasa, Suihkonena, Salomäkia, \& Selonen, 2012; Singh et al., 2011). Do they depend on the degree of influence on EF? Time? Or the production speed? Based on the integrated environmental management system, production levels and the technical HAZID environmental risk identification from construction to a cessation of mining activities, a graphical mapping has been achieved to observe a non-linearity of risks evolution over time. Indeed, by focusing on phases over time and production as explanatory and dependent variables, this latter does not have a symmetric role contrary to the correlation that one thinks to observe. This article shows a point cloud that can then be compared to ordinary least squares regression used to determine the extent to which a variable explanatory-dependent relationship affects the result (joint $x_{i}, \mathcal{Y}_{\mathrm{i}}$ ) which are related risks. Name of the linear regression technique in statistics, ordinary least squares allows by a linear relationship (in matrix form $\mathcal{Y}=\beta_{0}+x \beta+\mathcal{E}$ ) to adjust the cloud of points in a straight line called regression. Finally, the link between time and production as well as the sensitivity of the EFs was predicted by considering the paired T-test Student with simple linear regression (SLR) analysis.

\section{Research Methodology}

\subsection{Research Hypothesis}

Despite the fact of growing risks in the academic research world, risk knowledge in the industry environment, it is even more complex in mining because of much specificity. The existing tools for risk analysis are not directly applicable and so is it in mining. It's already known that risk is the product of exposure multiplied by consequences but, by intending a temporal representation of the risks, it is assumed here that the environmental risks are associated with mining production and time (per phase). The risk, therefore, depends on time (per phase), and this one varies linearly with the production.

\subsection{Materials and Methods}

By limiting the scope, this research aims to show: the real evidence of the intrinsic link between production, time (per phase), the risks involved and the opportunity to represent an approximate evolution of environmental hazards over time. To lighten the research methodology, water is the only EF considered and it is considered that the OPs operate similarly. The type of mine, the kind of material and the number of employees are not taken 
into the temporal risk assessment. This is done by a literature review about the environmental management risks tools existing, in-depth on the OPs and probability theories with SLR. Full results of this approach are summarized in section 4.

\subsection{Risks and Calculation Methods}

The risk notion defined by the probability of occurrence of a dangerous or unsafe condition amplified by the severity of the consequences of it, an overview of the proposed calculations of risk in the literature allowed keeping two (2) main known trends.

From Biron, Ivers, Brun, and Cooper (2006):

$$
\operatorname{Risk}(\mathrm{R})=\text { Probability of risk occurence }=\mathrm{E}(\text { exposure }) \times \mathrm{K}(\text { coping }) \times \mathrm{C}(\text { consequences })
$$

From Clarke and Cooper (2000):

$$
\text { Risk }(\mathrm{R})=\text { Probability of risk occurence }=\mathrm{E}(\text { exposure }) \times \mathrm{C}(\text { consequences })
$$

After analysis of risk score Bowles (2003) with Braband and Griebel (2004) believe that a simple multiplication is not appropriate. Then they proposed a logarithmic transformation with parameters having a scale from 1 to 10 to correct these lacunae as mentioned earlier:

$$
\mathrm{R}=\log _{\mathrm{b}}(\mathrm{IH})+\log _{\mathrm{b}}(\mathrm{POA})+\log _{b}(\mathrm{HD})+\log _{b}(\mathrm{RS})
$$

Where: IH is impact of hazard; POA is probability of occurrence of an accident; RS is the research specificities defined by the authors; HD (detectability of hazard) is defined by its reliability, availability, and selectivity. But the result is still monotone and also has a form even simpler than the product which could make hard to perform a detailed risk analysis when there is an interaction/combination of hazards. Therefore, the equation (1) is the one taken into account in this study. However, the consequences $(\mathrm{C})$ or coping $(\mathrm{K})$ levels values, belonging to a framework of OPs, for this research will be fixed at 1 for each risk. Then, the equation becomes:

$$
\mathrm{R}=\mathrm{E}(\text { exposure })=\text { Probability of risk occurrence }(0)
$$

According to Groso, Ouedraogo, and Meyer (2012) the probability of risk occurrence could be $\mathrm{O}=\mathrm{e}+2$ are $+\mathrm{L}$ (with: $\mathrm{e}-$ exposure frequency, po - probability, $\mathrm{L}-$ possibility to avoid or limit the damage) because of other authors like Bowles (2003) who found out that the general Eq. (1) leads to duplication of some risks based on changes in factors affected. Indeed, the risk scale is vast because of hypersensitivity to the slightest change in the affected elements, which result in impacts of various natures even if it's small changes. Then, the risk computation method finally retained is the probability of risk occurrence $(0)$ knowing the supply chain in time $(\mathrm{T})$ :

$$
\mathrm{R}=\text { Probability of risk occurrence }(0)=\mathrm{P}(\mathrm{O} \mid \mathrm{T})=\mathrm{P}(\mathrm{O} \cap \mathrm{T}) / \mathrm{P}(0)
$$

Before using these mathematical models, inventory of environmental risks related to the water that will be studied here must be done. 


\section{Macrothink \\ Environmental Management and Sustainable Development \\ ISSN 2164-7682 \\ 2018, Vol. 7, No. 4}

\subsection{Environmental Risks Associated with Water in an OP Mine}

Based on the integrated environmental assessment system, the methodology in this second part refers to the environmental risk assessment, which is to identify and prioritize risks despite the uncertainty of their occurrence. At this stage, the first step is to identify the environmental risks related to water in an industrial OP mine cause there are many differences with artisanal OP mine. This consists of determining which hazards affect the environment factors including humans by using a known technique. There is many risk identification variable, but the hazard identification (HAZID) method is selected here due to the coexistence of operations humans and the EFs. Indeed, as told Nakayama, Sakamoto, Kasai, Shibutani, and Miyake (2016) even there are some qualitative and quantitative methods like: the risk and operability study method (HAZOP), the failure mode and effect analysis method (FMEA), the fault tree analysis method (FTA) and so on. But HAZID combined both methods that lead to better risk management processes.

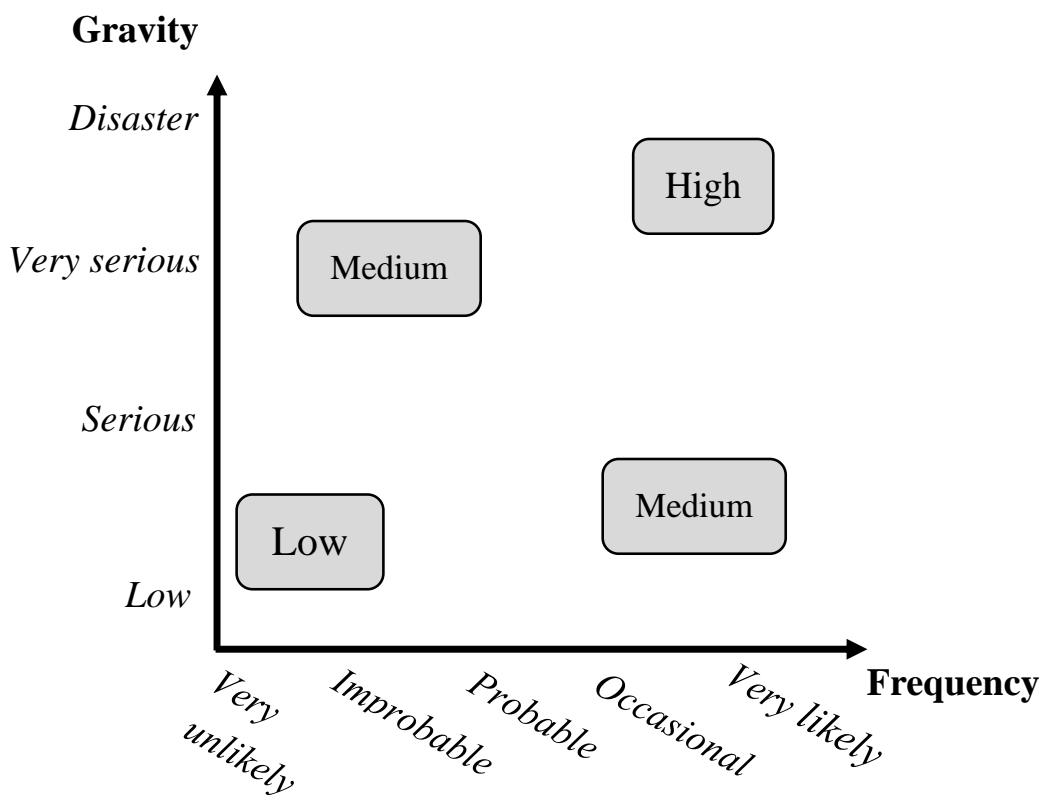

Figure 1. Risk assessment by prioritization

This technique allows obtaining a cloud of risk points with low, medium or high-risk priority like in Figure 1 above. But before, it's important to explain the way the graph of the evolution of risks based on production and mining phases in time has been built.

The $\mathrm{X}$-axis is scaled over an average fictitious value of 25 years since the construction of the mine to the cessation of extractives activities. This axis is divided into three main periods: $t_{1}$ $=$ construction with installations ( 0 to 5$), t_{2}=$ operation (5 to 19) and $t_{3}=$ cessation (19 to 25). The ordinate axis (Y-axis) on the other hand indicates the percentage of production up to $100 \%$. Then through the probability of occurrence risk equation for each period equivalent to the production level, a point is marked. Here is an example: the noise risk is permanently observed throughout all phases of any mine life cycle. But it is known that noise becomes awkward at the beginning of mine construction activities at 0.75 years so in less than a year of activities which corresponds to a low production certainly, around $12 \%$, but not negligible. 
So each data point along the graph is the result of interactions between the elements of time and the approximate level of production corresponding. This is how the cloud points corresponding to the risks have been represented. Obtaining this point cloud allows drawing a line going from an average closer to all points. This line is called a straight line of regression that will be used to validate the research hypothesis.

\subsection{Research Hypothesis Testing and Simple Regression Analysis}

This is done by estimating the linear regression parameters with T-test of student with a statistical tool. There are many statistical tools such as Microsoft Excel, Statistical Package for the Social Sciences (SPSS), Statistical tools for high-throughput data analysis (STHDA), and so on, but STHDA is which served in this study.

The regression is used in the prediction of quantitative variables, in knowledge of conditional average or another variant of this kind and for the analysis of relationships between variables. It also allows describing the endogenous variables associated with exogenous variables. So here, by validating the assumption that a function connects an explained variable with an explanatory variable, the SLR model also helps to demonstrate the uncertainty of the system due to risks. Here is the Eq. (6) in factorial form:

$$
y=\beta_{0}+x \beta+\mathcal{E}
$$

Where $\mathcal{Y}$ is random explained or dependent variable; $\mathcal{X}$ is independent or explanatory variable; $\beta_{0}$ is Y-intercept; $\beta$ is the slope; $\varepsilon$ is a random error term, unobserved, independent and identically distributed (Yu \& Yao, 2016).

Then, for each individual statistic under the Gaussian assumption, the equation system model is:

$$
\mathcal{Y}_{i}=\beta_{0}+\beta_{1} x_{i 1}+\beta_{2} x_{i 2}+\varepsilon_{i}
$$

Where $\beta_{0} \ldots \beta_{\mathrm{n}}$ are unknown and are assumed to be constants; $\mathcal{E}_{i}$ is a zero-expectation (Yerel \& Ersen, 2013).

But since there are only one dependent variable and one explanatory variable in this study's context, there will be no extension to the multiple linear regression and the final equation is:

$$
y_{\mathrm{i}}=\beta_{0}+\beta_{1} x_{\mathrm{i}},
$$

Where $\beta_{0} \ldots \beta_{\mathrm{n}}$ are assumed to be constants; $\mathcal{Y}$ the dependent variable; $\mathcal{X}$ the independent or explanatory variable.

Finally, when the regression line equation is determined, the T-test Student approach also known as Student's paired test, in this case, is used to validate the research hypothesis by comparing the variable groups. Indeed, it is a paired T-test because both groups are from the same OP mine.

\subsection{T-test Student Principle}

This test is any statistical hypothesis test that enables to accept or reject the formulated hypothesis. The general hypothesis is: «the risk depends on time (per phase), and this one 
varies linearly with the production», but it is necessary to formulate the statistical hypothesis: $\mathrm{H}_{0}, \mathrm{H}_{1}$.

The null hypothesis $\left(\mathrm{H}_{0}\right)$ means that there is no significant distinction between the averages of two variables groups as follows: $\beta_{0}=\beta_{1}$. Contrary to the null hypothesis, the alternative hypothesis $\left(\mathrm{H}_{1}\right)$ corresponding to the general assumption states that there is a significant difference between the averages of the two groups, so $\beta_{0} \neq \beta_{1}$. It is the existence of this difference (by rejecting the null hypothesis) that allows inferring the existence of a link between $\beta_{0}$ and $\beta_{1}$.

As a reminder, let recall that in human sciences, the significance level is 0.05 corresponding to the risk alpha $=5 \%$ for one degree of freedom $($ d.f. $=n-1)$. Also, it is important to note that the hypothesis here is bilateral due to $H_{0}\left(\beta_{0}=\beta_{1}\right)$ and $H_{1}\left(\beta_{0} \neq \beta_{1}\right)$. If the T-value is calculated, the probability value ( $\mathrm{p}$-value: the observed level of importance for this test) could be compute also and it's compared to the significance level. Usually, T-value is manually given by the mathematical formulation below.

$$
\mathrm{T}=\mathrm{m} / \mathrm{s} / \sqrt{\mathrm{n}},
$$

Where $\mathrm{m}$ is the mean of the difference between the two measures for each observation pair; $\mathrm{s}$ is the standard deviation of the difference between the two measures for each observation pair; and, $\mathrm{n}$ is the size of the series of observation pairs.

But, being supported by other programs, the calculation has been made directly with STHDA. So, if $\mathrm{p}$-value $>0.05$, the null hypothesis must be accepted that there is no significant difference between $\beta_{0}$ and $\beta_{1}$. But, if the p-value is $<0.05$ : the null hypothesis will be dismissed and then, obviously there will be an important link between $\beta_{0}$ and $\beta_{1}$.

\section{Results}

\subsection{Ecosystem Components Dependent on Water}

The consumption of water in the mines is considerable. For example, from 2011 with 8.9 million m3, Agnico-Eagle Mines Limited ${ }^{\mathrm{TM}}$ has decreased the volume of discharged effluent in 2012 to 7.2 million $\mathrm{m} 3$ (Grondin, 2012). This is still a significant amount for a company among so many others. Described as a unique solvent by Falkenmark (2001) is the water carrier to the time of solutes, sediment and other materials through various spectra of the environment. For this reason, although it is an EF, it is directly and indirectly linked to different elements of the ecosystem to which it belongs. Thus, once contaminated or destabilized, it becomes a vector, a factor or a source of risk that affects all the elements to which it is itself linked to an industrial activity such as mining. In Figure 2 below these elements are illustrated. Moreover in mining, contaminants, and composition of ore or waste rock can change, by reactions when exposed to light and air, water characteristics with the risk of rendering it unusable. 


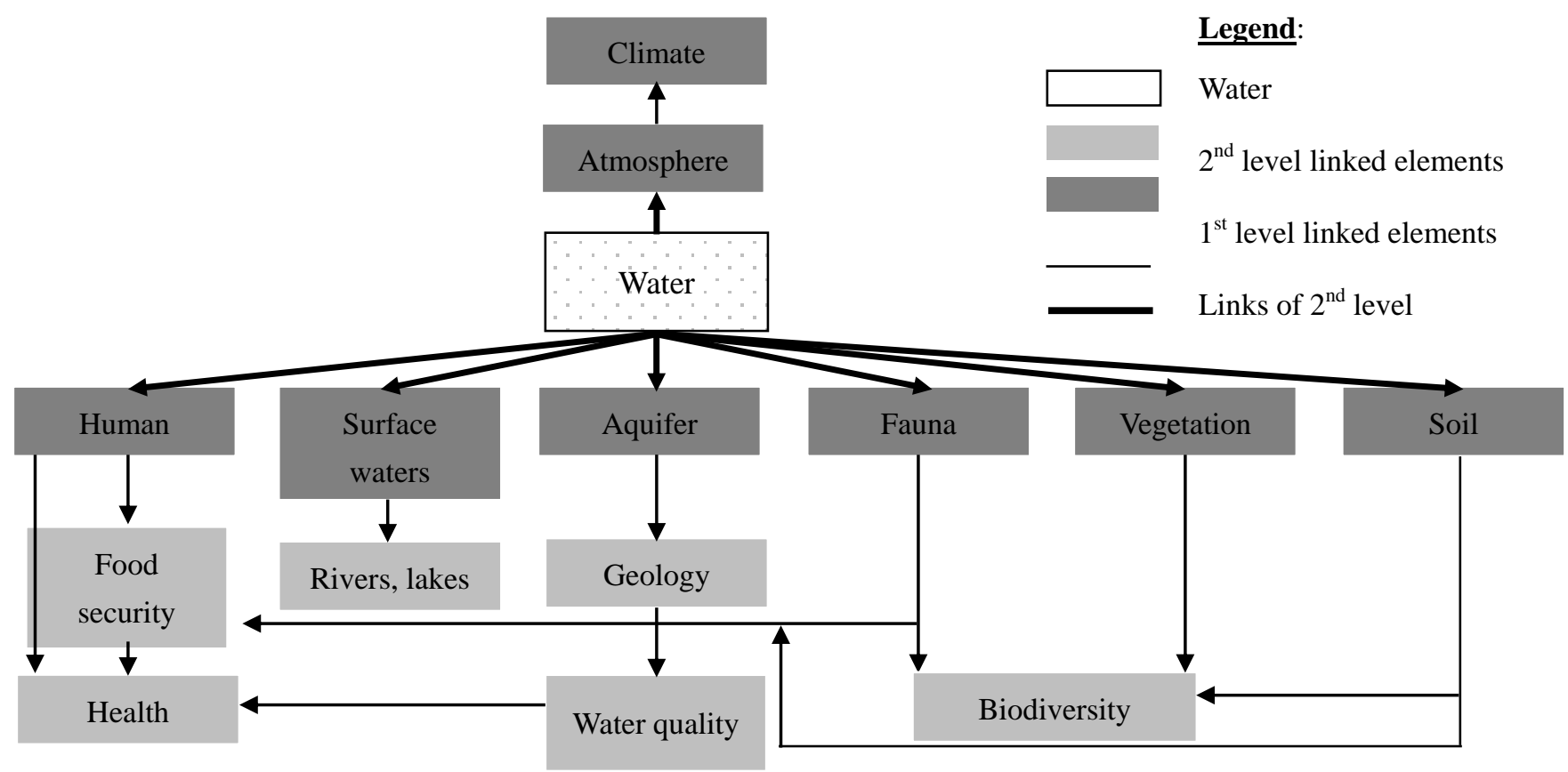

Figure 2. Description of the work methodology

For example, the enrichment process that aims to achieve a high concentration of these metals regarding production is a significant source of chemical use and contaminated water emissions (Mballo, 2012). Here is why Soni and Wolkersdorfer (2016) emphasized the need to know the aspects of water management around the mines. And these thoughts induced the illustration in Figure 3 below about areas use of water in the production process in OP mine.

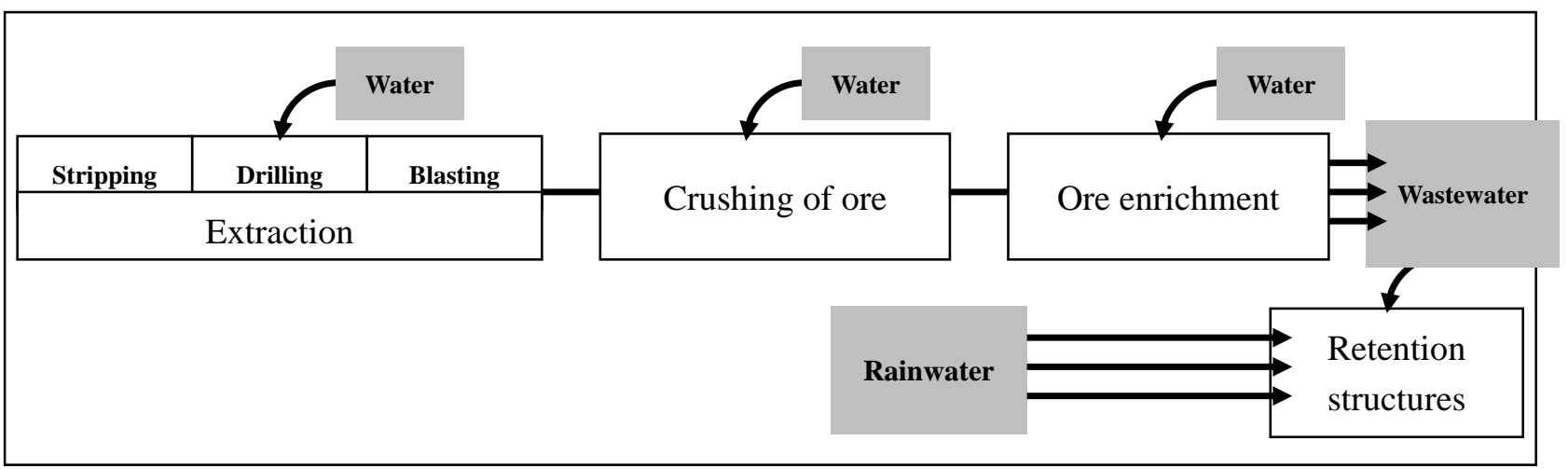

Figure 3. Areas use of water in the OP mining process

\subsection{Risks Identification Related to Water}

Based on the fundamental principle of the systems, the next step before the mapping of risks linked to water is to identify at best through appropriate hazards identification techniques, the risks incurred from use of water in mining operations. The identification here by HAZID in Figure 4 was made according to each phase of time and EF afterwards. 


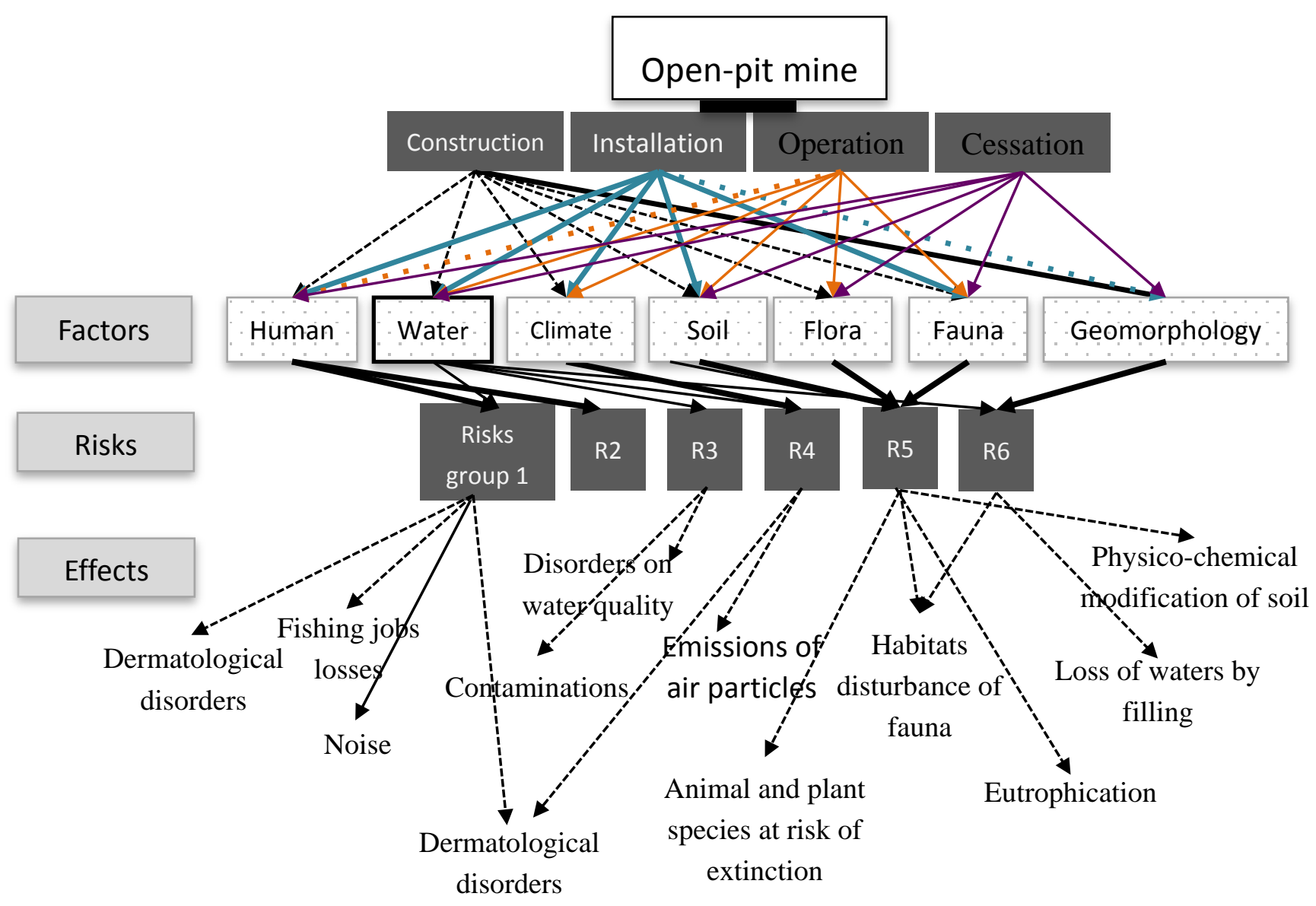

Figure 4. Identification and risk characterization related to water through HAZID method

\subsection{Qualitative and Quantitative Data from Matrix of Symbol Values or Numerical Matrix}

Identifying these risks demonstrates the synergy in which they operate. Authors like Teparut and Sthiannopkao (2011) and George et al. (2010) have documented the impacts on physicochemical characteristics of water and other EF related to water. While many efforts are combined today by mining to fit better with the principles of sustainable development, the environmental consequences of mining on water remain numerous and affect many aspects of our ecosystem, including humans. Apparently, the water-related environmental risks seem to be a major concern which needs solutions. However, the temporal effect has been added to the probability of occurrence $(O)$ in Eq. (5) to identify each risk in the graphic. But it is worth remembering that all identifiable risks are not present in this study.

\subsection{The Risks Temporal Mapping}

Through a list of risks already identified in the scientific literature, this temporal graph below shows the gradual or repetitive proliferation of environmental risks according to changes in mining activities over time. It is important to note here that list is a non-exhaustive 


\section{Macrothink \\ Environmental Management and Sustainable Development \\ ISSN 2164-7682 \\ 2018, Vol. 7, No. 4}

recapitulated mapping of the related risks to water in OP mine.

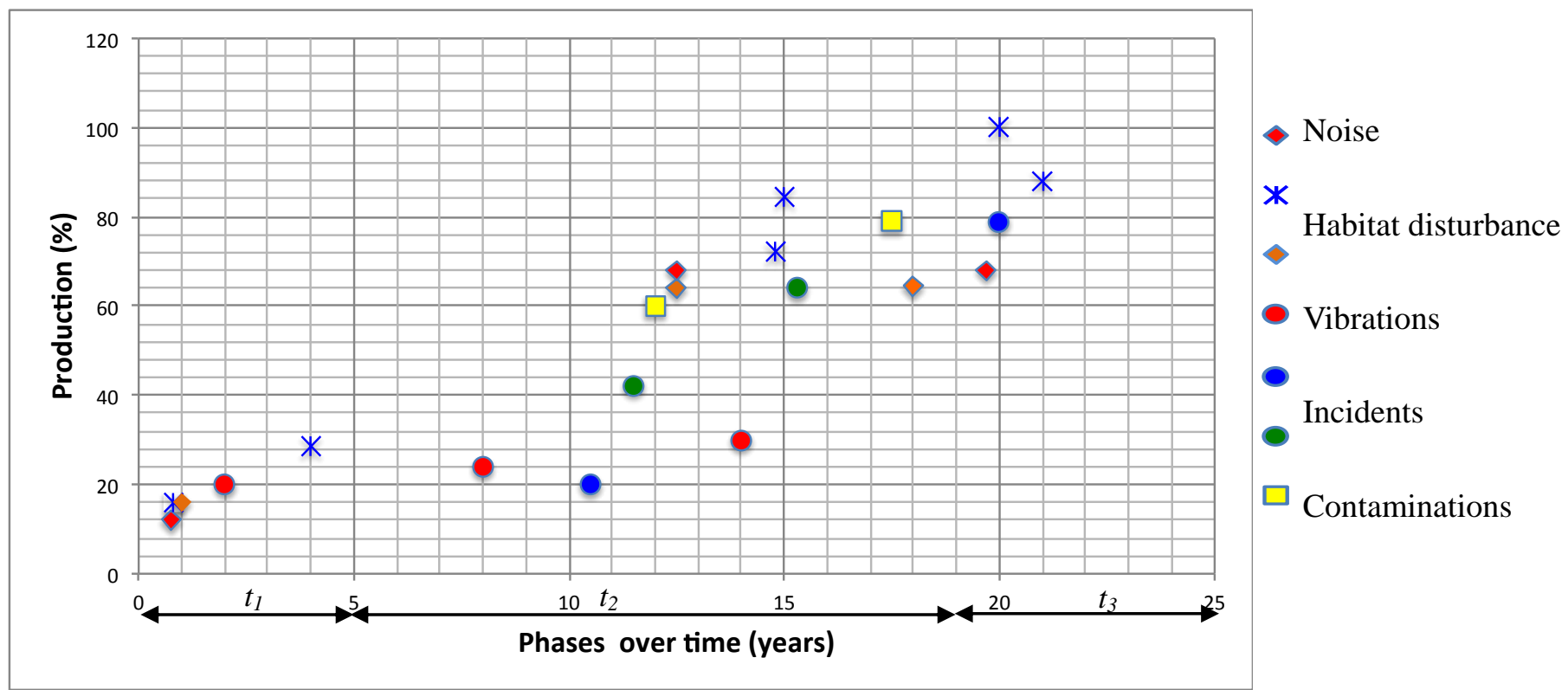

Figure 5. Graphical clouds of few environmental risks related to the water factor

\subsection{The Linear Regression Line and Validation of the Assumption}

The regression line obtained in Figure 6 by knowledge of the researcher, the literature review and the Bayesian theory, the validation of the research hypothesis, has to be achieved first before completing the validation.

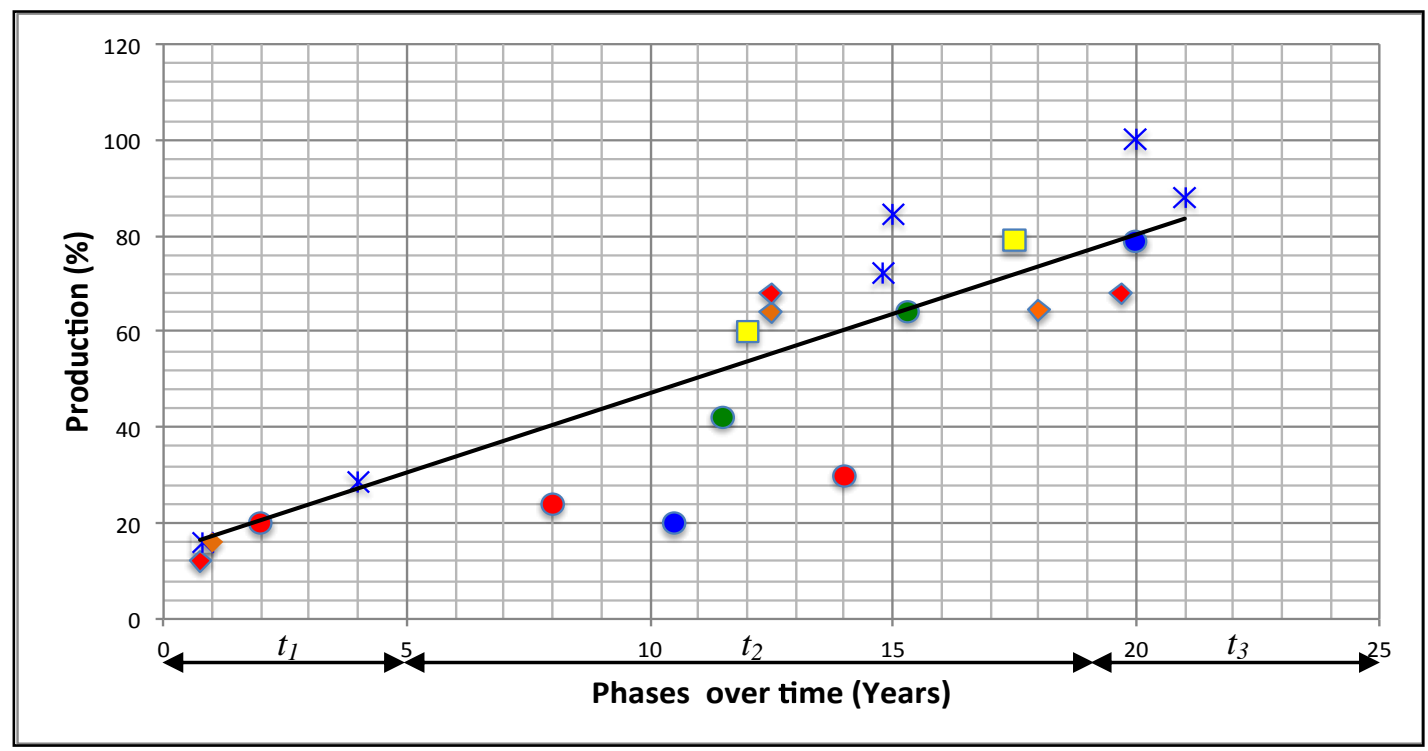

Figure 5. Evolution of the linear regression line over time

In this study, there are 21 observations pairs shown in Table 1 with the respective variables. 
Table 1. Observations pairs with the corresponding variables

\begin{tabular}{|c|c|c|c|}
\hline Observations pairs & Risk type & $x$ & $y$ \\
\hline 1 & Noise & 0,75 & 12 \\
\hline 2 & Habitats disturbance & 0,8 & 16 \\
\hline 3 & Vibrations & 1 & 16 \\
\hline 4 & Incidents & 2 & 20 \\
\hline 5 & Habitats disturbance & 4 & 28,5 \\
\hline 6 & Incidents & 8 & 24 \\
\hline 7 & Contaminations & 10,5 & 20 \\
\hline 8 & Filling stream & 11,5 & 42,3 \\
\hline 9 & Eutrophication & 12 & 60 \\
\hline 10 & Vibrations & 12,5 & 64 \\
\hline 11 & Noise & 12,5 & 68 \\
\hline 12 & Incidents & 14 & 30 \\
\hline 13 & Perturbation des habitats & 14,8 & 72 \\
\hline 14 & Habitats disturbance & 15 & 84,5 \\
\hline 15 & Filling stream & 15,3 & 64 \\
\hline 16 & Eutrophication & 17,5 & 79 \\
\hline 17 & Vibrations & 18 & 64,4 \\
\hline 18 & Noise & 19,7 & 68 \\
\hline 19 & Contaminations & 20 & 79 \\
\hline 20 & Habitats disturbance & 20 & 100 \\
\hline 21 & Other disturbances & 21 & 88 \\
\hline
\end{tabular}

However, given the importance of validating the assumption and clouds of risk points (involved about water factor), statistical methods to analyse and explore the relationships between one or several variables have been scanned. Among them, as it said in section 3, the T-test of student appears to be the most appropriate. Here is the result in Table 2.

Table 2. Paired T-test results with the corresponding variables

\begin{tabular}{|c|c|c|c|}
\hline T & d.f. & p-value & Confidence interval (95\%) \\
\hline-8.328 & 20 & $6.231 \mathrm{e}^{-08}$ & {$[-50.546,-30.2969]$} \\
\hline
\end{tabular}

\begin{tabular}{|c|c|c|c|}
\hline Groupe & $\boldsymbol{n}$ & $\boldsymbol{m}$ & $\boldsymbol{s}$ \\
\hline$x_{i^{1}}$ & 21 & 11.9452 & 6.7905 \\
\hline$x_{i 2}$ & 21 & 52.3667 & 28.0031 \\
\hline
\end{tabular}

In the result above: $\mathrm{T}=-8.328$ is the Student statistic; d.f. $=20$; Probability value ( $\mathrm{p}$-value) is the degree of significance test $\left.=6.231 \times 10^{-08}\right)$. Finally, the confidence interval of the 
difference of means to $95 \%$ is $=[-50.546,-30.2969]$.

$$
\begin{gathered}
\mathrm{p}-\text { value }=6.231 \times 10^{-08}=0,0000000623<0,05 \\
\text { As } \mathrm{p}-\text { value }<0,05, \mathrm{H} 0 \text { is rejected }
\end{gathered}
$$

The p-value of this paired test is $6.231 \times 10-08$, which is much lower than 0.05 . Then it can be therefore stated that the environmental risks depend on time, and they vary linearly with the mining production with a $\mathrm{p}-$ value $=6.231 \times 10^{-08}$.

\section{Discussion}

The research purpose was to confirm if environmental risks depend on time and vary linearly with the production. Of course, the use of a particular technique depends on the aims of the analyses, so simple regression analysis has been chosen. The prediction of value by using the linear regression analysis is an important aspect used in mining issues by some authors like Yerel et Ersen (2013) but not associated with environmental management. Here particularly, it's applied to determine the real relationship between dependent variable production (\%) and independent variable phases over time (year). Despite their differences, a harmony can exist and it has been found in statistics with the simple regression analysis. SLR modelling in the presence of the straight line of regression in Figure 6, which has been dealt to validate the hypothesis and address, the relevant issues about the influence of production and time on hazardous situations for environment and humans. The regression line is plotted to point out the links between production (\%) and phases over time (year). Then, the statistical significance and validity of the research hypothesis have been checked by using the paired T-test student previously described.

The $\mathrm{p}$-value of the model is $6.231 \times 10-08$, which is equivalent to $\mathrm{p}$-value $<0.05$. Since it is concluded that there is a statistically significant relation between production $(\%)$ and phases over time (year) at the $95 \%$ confidence interval. Thus, by rejecting the null hypothesis $(\mathrm{H} 0)$, $\beta_{0} \neq \beta_{1}$ and, the model is statistically valid.

The involvement of water as a fundamental element of mining operations (Fig. 3) and intrinsically linked to the other EF (Fig. 2) shows his aptitude to act as a diffuse source of various risks in case there is contamination (Fig. 4). Indeed, by ecohydrological interactions, the contaminants affect the chemistry, biology, environment, productivity, water quality and viability also. A dynamic interaction, demonstrating the plurality of negative impacts arising from the imbalance of an ecosystem factor which covers, in turn, more than one factor. And this, despite the scientific efforts made to fit better with sustainable development principles. Several types of research studies including those by Jordan et al. (2004) and Falkenmark (2011) jointly with other academic studies have stated irregularities in certain aspects of water-related policies. But, the study outlines why it is worth remembering that knowing in depth all the risks associated with water in mining should be the starting point in environmental hazards management. Obviously, all these phenomena also demonstrate the synergy in which mining operations are performed, how to appear and evolve the risks in each step.

To understand it in more details, the temporal mapping designed in section 4.3 (Fig. 6) indeed 
shows the occurrence of risks, their apparition order, but, above all a proliferation and persistence of some risks in time. This explains why by taking into account effect, probability and consequence of each risk actually considered in risk formula - Eq. (5): 1) the extent of some risks is amplified over time; 2) there are also certain risks which recur, and; 3) some risks frequently involved. Furthermore, it is obvious to see that the probability of occurrence value of each risk can only be approximative because of the sensitivity of the sources of risk and ecosystem diversity. So, the result just illustrates the cumulative effects all along the life of an OP mine with the repetition of some operations and amplification of impacts such as various disturbances, noise, and vibrations until production ceases. This plurality of environmental risks, thus recognized, the susceptibility of EFs, the diversity of deposits of minerals and mining operations associated with, can testify the difficulties to effectively solve environmental problems with current tools. But, through the use of this dynamic approach in future work with some tools that meet the basic principles of dynamic systems, it is possible to contribute to intensive changes in the environmental risk management system in OP mines, underground also and other similar industries such as manufacturing.

\section{Conclusion}

Due to the identification of points of water entry into OP mine, the mapping of environmental risks related has fostered the exhibition of partial ecohydrological interactions in mining. The analysis allows deducting some dynamic parameters, which are $75 \%$ sources of risk on the site and around them. We have: 1) extraction procedures, which may vary from OP or minerals to another; 2) enrichment processes, and; 3) the type of wastewater retention structures.

Mining is one of the most influential sectors in the world economy. The results here are rather optimistic and show that the model defined could help early to integrate quantitatively at the planning, impacts of the operations. According to this research the temporal representation of the related risks to water in OP mines highlights a dynamic analysis with a nonlinear combination of severity, probability as an environmental hazards dashboard. For this reason, the environmental risks management tools for mining may improve worldwidely if we include the linear regression analysis. Since environment is a global state of ecosystems, this approach must be extended to all EFs in future research but, by taking in account the polynomial function of risks arising from the interactions, multiple linear regression analysis can be more useful. Furthermore, this work is helpful for dynamic systems and other perspectives like the development of better environmental risks management tools in mining.

\section{Acknowledgment}

The authors kindly thank the representatives of the School of High Studies in Public Health (École des Hautes Études en Santé Publique, EHESP) in France and the University of Sherbrooke in Canada for the possibility given to set out a partial communication of this work at the $84 \mathrm{e}$ ACFAS. They also recognize the constructive involvement of theirs supervisors and Ms. Osseni Achabi Chakirath.

\section{References}


Biron, C., Ivers, H., Brun, J.-P., \& Cooper, C. L. (2006). Risk assessment of occupational stress: Extensions of the Clarke and Cooper approach. Health, Risk \& Society, 8(4), 417-429. https://doi.org/10.1080/13698570601008222

Bowles, J. B. (2003, 27 - 30.1.2003). An assessment of RPN prioritization in a failure modes effects and criticality analysis. Paper presented at the Annual Reliability and Maintainability Symposium, Proceedings, Tampa, FL, USA.

Braband, J., \& Griebel, S. (2004, 30.06 - 2.07.2004). Engineering a simple, yet rigorous, Risk Analysis Method. Paper presented at the Proceedings, the Irish Signals and Systems Conference 2004: ISSC 2004, Queen's University Belfast, Northern Ireland, Rhode Island.

Clarke, S. G., \& Cooper, C. L. (2000). The risk management of occupational stress. Health, Risk \& Society, 2(2), 173-187. https://doi.org/10.1080/713670158

Falkenmark, M. (2001). The Greatest Water Problem: The Inability to Link Environmental Security, Water Security and Food Security. Water Resources Development Journal, 17(4), 539-554. https://doi.org/DOI:10.1080/07900620120094073

Falkenmark, M. (2011). Water - A reflection of land use: Understanding of water pathways and quality genesis. International Journal of Water Resources Development, 27(1), 13-32. https://doi.org/10.1080/07900627.2010.536943

George, J., Thakur, S. K., Tripathi, R. C., Ram, L. C., Gupta, A., \& Prasad, S. (2010). Impact of coal industries on the quality of Damodar river water. Toxicological \& Environmental Chemistry Journal, 92(9), 1649-1664. https://doi.org/10.1080/02772241003783737

Grondin, L. (2012). Résumé du rapport sur la responsabilité sociale d'entreprise 2012 (AEM-2012-CSRFR-REPORT). Toronto, ON, Canada: A. E. M. Limitée.

Groso, A., Ouedraogo, A., \& Meyer, T. (2012). Risk analysis in research environment. Journal of Risk Research, 15(2), 187-208. https://doi.org/10.1080/13669877.2011.634513

Jordan, G., D’Alessandro, M., Hamor, T., Liedekerke, M. V., Panagos, P., Puura, E., ... Vijdea, A. M. (2004). Mining Waste and Related Environmental Issues: Problems and Solutions in Central and Eastern European Candidate Countries (EUR 20868 EN): P. Office.

Kalabin, G. V. (2012). Principles of macro-ecological risk mapping of mining industry areas. Journal of Mining Science, 48(6), 1071-1078. https://doi.org/10.1134/S1062739148060172

Kř́beka, B., De Vivob, B., \& Davies, T. (2014). Special Issue: Impacts of mining and mineral processing on the environment and human health in Africa. Journal of Geochemical Exploration, 144(Part C), 387-390. https://doi.org/10.1016/j.gexplo.2014.07.018

Lintukangasa, M., Suihkonena, A., Salomäkia, P., \& Selonen, O. (2012). Post-Mining Solutions for Natural Stone Quarries Journal of Mining Science, 48(1), 142-154.

Mballo, B. (2012). Impacts possibles des activites minieres sur les ressources en eau en Afrique de l'ouest : cas des mines aurifères du Burkina Faso. (Master Mémoire). institut international d'ingéniérie, de l'eau et de l'environnement (2IE), Ouagadougou, Burkina Faso. 


\section{Macrothink}

Environmental Management and Sustainable Development

ISSN 2164-7682

2018, Vol. 7, No. 4

Nakayama, J., Sakamoto, J., Kasai, N., Shibutani, T., \& Miyake, A. (2016). Preliminary hazard identification for qualitative risk assessment on a hybrid gasoline-hydrogen fueling station with an on-site hydrogen production system using organic chemical hydride. International Journal of Hydrogen Energy, 41(18), 7518-7525.

https://doi.org/10.1016/j.ijhydene.2016.03.143

Peck, P., \& Sinding, K. (2003). Environmental and social disclosure and data richness in the mining industry. Business Strategy and the Environment, 12(3), 131-146.

https://doi.org/10.1002/bse.358

Pokhrel, L. R., \& Dubey, B. (2013). Global Scenarios of Metal Mining, Environmental Repercussions, Public Policies, and Sustainability: A Review. Critical Reviews in Environmental Science and Technology, 43(21), 2352-2388.

https://doi.org/10.1080/10643389.2012.672086

Singh, K., Ihlenfeld, C., Oates, C., Plant, J., \& Voulvoulis, N. (2011). Developing a screening method for the evaluation of environmental and human health risks of synthetic chemicals in the mining industry. International Journal of Mineral Processing, 101(1-4), 1-20.

https://doi.org/10.1016/j.minpro.2011.07.014

Soni, A. K., \& Wolkersdorfer, C. (2016). Mine water: policy perspective for improving water management in the mining environment with respect to developing economies. International Journal of Mining, Reclamation and Environment, 30(2), 115-127.

https://doi.org/10.1080/17480930.2015.1011372

Statcan. (2012). Industrial Water Use (Catalogue no. 16-401-X). Ottawa, ON, Canada: M. o. industry.

Teparut, C., \& Sthiannopkao, S. (2011). Mae Moh lignite mine and environmental management. Geosystem Engineering, 14(2), 85-94.

https://doi.org/10.1080/12269328.2011.10541335

Yerel, S., \& Ersen, T. (2013). Prediction of the calorific value of coal deposit using linear regression analysis. Energy Sources, Part A: Recovery, Utilization, and Environmental Effects, 35(10), 976-980. https://doi.org/10.1080/15567036.2010.514595

Yu, C., \& Yao, W. (2016). Robust linear regression: A review and comparison. Communications in Statistics - Simulation and Computation, 1-38.

https://doi.org/10.1080/03610918.2016.1202271

\section{Copyright Disclaimer}

Copyright for this article is retained by the author(s), with first publication rights granted to the journal.

This is an open-access article distributed under the terms and conditions of the Creative Commons Attribution license (http://creativecommons.org/licenses/by/3.0/). 